\title{
TEORIA E HISTÓRIA NA SOCIOLOGIA BRASILEIRA: A CRÍTICA DE MARIA SYLVIA DE CARVALHO FRANCO* \\ André Botelho
}

Para Nísia

Em Homens livres na ordem escravocrata, Maria Sylvia de Carvalho Franco investiga as relações entre homens livres no Vale do Paraíba, ao longo do século XIX, com o objetivo principal de mostrar como, no Brasil, se constituiu um princípio mais geral de coordenação das relações sociais, que chama de "dominação pessoal", desdobrada no Estado e nas práticas de mercado. Com sua pesquisa, a autora não intentou, porém, caracterizar ou qualificar esse tipo de associação moral que ligava homens livres pobres e fazendeiros como marca de uma sociedade tradicional, ou atrasada, ou ainda incompatível com os processos de mudança social e o dinamismo que o capitalismo ia assumindo também entre nós. Em verdade, toda argumentação do livro visa, ao contrário, desmontar essa visão sobre a sociedade brasileira.

\footnotetext{
* Este estudo é parte de pesquisas mais amplas ainda em curso, financiadas pelo CNPq e pela Faperj, que também vem envolvendo orientações acadêmicas. Agradeço a Maurício Hoelz Veiga Jr., Paloma Malaguti e Pedro Cazes. O estudo foi apresentado no GT Pensamento social brasileiro, durante o $36^{\circ}$ Encontro Anual da Anpocs (2012), a cujos membros também sou grato.
} 
Visão persistente e que, aos olhos da autora, se renovava com a autoridade das ciências sociais, especialmente a partir da adoção de paradigmas do funcionalismo norte-americano, em diferentes perspectivas, sobre a modernização que a autora acaba reunindo sob a designação de "sociologias do desenvolvimento". Maria Sylvia de Carvalho Franco tem em vista, portanto, a então influente teoria da modernização de Talcott Parsons, mas também a tradução da sociologia weberiana a partir desta tradição e sua transplantação direta para o estudo da realidade latino-americana, em geral, e brasileira, em particular. Perspectivas que, a seu ver, transformavam relações históricas em modelos abstratos, isolando variáveis e construindo séries temporais desconectadas dos processos históricos concretos e variáveis. Essa posição se desdobra em diferentes níveis no conjunto da sua obra sociológica, aparecendo também como tema recorrente nas várias entrevistas que a autora tem concedido ao longo de muitos anos.

A hipótese geral da pesquisa em que o presente estudo se insere é que a crítica de Maria Sylvia de Carvalho Franco às interpretações da sociedade brasileira identificadas com as teorias da modernização da sua época, recoloca em debate as relações mais amplas entre teoria e história na sociologia brasileira, com efeitos teóricos heurísticos para pensarmos a contemporaneidade. Espécie de denominador comum a essas interpretações, constituindo-as e deformando-as, seria o modo disjuntivo como as relações históricas foram tomadas como polaridades conceituais antitéticas, como "tradição" e "modernidade", a que a autora se contrapõe. Assim, em sua obra, Maria Sylvia de Carvalho Franco recoloca em questão o problema da historicidade da vida social para a sociologia, em uma análise fina que busca esclarecer as conexões de sentido que o processo histórico-social engendra entre categorias e relações sociais.

As conclusões da sua tese de doutorado Homens livres na velha civilização do café, orientada por Florestan Fernan- 
des, defendida em 1964 perante a comissão examinadora composta por Antonio Candido, Sérgio Buarque de Holanda, Octavio Ianni e Francisco Iglesias, além do orientador, e publicada como livro cinco anos depois, com o título Homens livres na ordem escravocrata, parecem ter levado a autora a questionamentos teóricos mais amplos e profundos sobre o problema da historicidade da vida social. É desse tema que se ocupa especialmente em sua tese de livre-docência, defendida em 1970 junto ao Departamento de Ciências Sociais da Universidade de São Paulo, intitulada $O$ moderno e suas diferenças. Por isso, é preciso reconectar a interpretação substantiva do Brasil feita em Homens livres na ordem escravocrata a essas formulações teóricas contemporâneas e posteriores. Quanto a estas, concentrar-me-ei na sua interpretação de Max Weber, e seu esforço em ressignificar o sentido histórico das construções típico-ideais, a seu ver, indevidamente transformadas em modelos abstratos e recursos de generalização a-históricos. Um breve contraponto com a interpretação de Fernando Henrique Cardoso a respeito do caráter patrimonial e estamental da sociedade brasileira nos ajudará a situar de modo menos abstrato as ponderações teóricas da autora.

Maria Sylvia de Carvalho Franco esteve ligada à Universidade de São Paulo desde 1949, quando ingressou no curso de Ciências Sociais, nele se bacharelando em 1952. Entre 1955 e 1969, integrou como assistente a cadeira de Sociologia I, sob a direção de Florestan Fernandes, que reunia ainda Fernando Henrique Cardoso, Octavio Ianni, Renato Jardim Moreira, Marialice Foracchi, Celso Rui Beisiegel, Leôncio Martins Rodrigues Neto, entre outros. Sua pesquisa de doutoramento foi defendida em 1964 e publicada como livro apenas cinco anos depois, como já citado, pelo Instituto de Estudos Brasileiros (IEB), da própria USP. Embora possuam a mesma estrutura geral de capítulos, com apenas algumas alterações internas a eles, as duas versões do tra- 
balho guardam algumas diferenças de redação, sendo as mais importantes encontradas na introdução, que foi, em sua maior parte, suprimida da versão em livro. Nela, Maria Sylvia de Carvalho Franco realiza uma discussão detalhada e articulada dos temas da herança portuguesa, expansão ultramarina e escravidão. É verdade que, num tipo de intertextualidade muito própria à obra sociológica da autora, em que inclusive algumas partes dos seus escritos mais antigos reaparecem parcial ou quase integralmente em publicações posteriores, a discussão sobre a escravidão colonial moderna e o surgimento do capitalismo, suprimida da introdução do livro de 1969, seria retomada, entre outros escritos, como tema do artigo "Organização social do trabalho no período colonial”, publicado na revista Discurso, em 1978, e apresentado em um seminário na Unicamp nos anos 1980. Para Maria Sylvia de Carvalho Franco, a demora na publicação da tese sugere bem "sobre o teor da pesquisa realizada 334 e sobre as resistências que enfrentou. Do lado conservador, foi recusado por ser marxista; pela esquerda, foi recusado por não ser 'ortodoxo'” (Franco, 1988, p.16) - como avaliou em seu Memorial Acadêmico apresentado para o Concurso de Professor Titular do Departamento de Filosofia da USP, em 1988, para onde se transferira em 1970, durante a intervenção da ditadura militar naquela universidade. Nas décadas de 1970-80, Maria Sylvia de Carvalho Franco seguiu lecionando, pesquisando e orientando trabalhos no Departamento de Filosofia da USP, transferindo-se para a Unicamp no final dos anos 1980, e, mesmo aposentada, tem produzido em diversos campos da filosofia e publicado artigos na imprensa de grande circulação até o presente.

Em trabalho anterior (Botelho, 2007), sugeri que a obra sociológica de Maria Sylvia de Carvalho Franco constitui o ponto de chegada mais consistente em termos teórico-metodológicos da formação de uma sociologia política no Brasil. Formada entre os anos 1920-70, essa vertente 
bastante heterodoxa do ponto de vista doutrinário e político envolve ensaios de Oliveira Vianna e pesquisas acadêmicas realizadas, entre outros, por Victor Nunes Leal, Luís de Aguiar da Costa Pinto, Maria Isaura Pereira de Queiroz, além da própria Maria Sylvia de Carvalho Franco. Investigando diferentes fenômenos políticos, como clãs rurais, clientelismo, lutas de famílias, voto de cabresto e dominação pessoal, os trabalhos analisados convergem, no plano teórico-metodológico, para uma abordagem que se quer diferencialmente sociológica da política. Por abordagem "sociológica" entende-se aqui a ênfase nas bases sociais do Estado e da vida política, em suas relações com a estrutura social e as condições de protagonismo dos atores sociais, no lugar de uma lógica institucional autônoma que viria a caracterizar, em grande medida, o desenvolvimento da ciência política no Brasil (Lamounier, 1982). Ao articularem aquisição, distribuição, organização e exercício de poder político à estrutura social, aqueles trabalhos recusam a ideia de que as instituições seriam por si mesmas capazes de transformar a dinâmica social e, portanto, pudessem constituir variáveis autônomas na explicação do Estado e da vida política.

Ao aproximar Homens livres na ordem escravocrata dessa sequência sociológica cognitiva - e não institucional ou político-ideológica - flagrei a possibilidade de, estabelecendo uma visão diacrônica das ideias sociológicas, entre outras coisas, problematizar alguns aspectos reificados nas análises da história das ciências sociais no Brasil. No caso de Maria Sylvia de Carvalho Franco, por exemplo, fica relativamente claro o quão problemática pode ser uma abordagem exclusiva ou preponderantemente institucional de sua produção, uma vez que seu pertencimento à cadeira de Sociologia I da USP dificilmente pode ser traduzido diretamente em termos de orientação intelectual e realização cognitiva. O pertencimento institucional 
parece poder ajudar a entender, no máximo, a definição de uma agenda intelectual e as disputas que se desenrolam em torno dela, mas, ainda assim, de modo limitado, uma vez que outros fatores contextuais de ordens muito diversas também atuam na modelagem das trajetórias - como as clivagens sociais de origem socioeconômica (Pulici, 2008) e de gênero (Spirandelli, 2009), já abordadas em relação à Maria Sylvia de Carvalho Franco. A perspectiva institucional ajuda menos ainda, por outro lado, a esclarecer os sentidos teóricos heurísticos de uma obra. Sendo esse o caso, como neste estudo, o corpo a corpo com a obra e com os arquivos de documentos continua sendo recurso incontornável na pesquisa do pensamento social ou de teoria social comparada.

A "sociologia política" de Maria Sylvia de Carvalho Franco não apenas discrepa da orientação vigente na cadeira de Sociologia I, como pode mesmo ser considerada 336 uma crítica potente dos pressupostos de grande parte dos trabalhos nela desenvolvidos. Em importante artigo sobre a sociologia política forjada nesse espaço institucional, Brasilio Sallum Jr. (2002) mostra como as pesquisas realizadas por Florestan Fernandes e seu grupo de alunos e assistentes, especialmente Fernando Henrique Cardoso e Octavio Ianni, não apenas estabelecem a associação entre dominação política e conflito de classes, como as articula às questões da dependência e do desenvolvimento econômicos. Ora, o argumento crucial deste estudo é que a sociologia política de Maria Sylvia de Carvalho Franco pode ser entendida como um tipo de contraposição crítica persistente à ideia, presente nas teorias da modernização, de que as inovações modernizadoras funcionariam como variáveis sistêmicas interligadas e intercambiáveis de modo (relativamente) independente dos seus contextos históricos. $\mathrm{O}$ que recoloca em discussão, de maneira pungente, a relação entre teoria e história na sociologia. 


\section{Homens livres na ordem escravocrata: uma unidade contraditória}

A primeira, e talvez, mais decisiva característica da pesquisa de doutoramento de Maria Sylvia de Carvalho Franco, Homens livres na velha civilização do café, que permite problematizar a naturalização de suas relações com a orientação intelectual de Florestan Fernandes e da cadeira de Sociologia I da USP, é a recusa da autora em tratar a escravidão como um "modo de produção" que teria estruturado a sociedade brasileira, determinando todo o seu desenvolvimento posterior ${ }^{1}$. Naquele âmbito, no início da década de 1960, apareceram os principais resultados de um programa consistente de investigação liderado por Florestan Fernandes sobre escravidão e racismo. Dentre as pesquisas estavam Capitalismo e escravidão no Brasil meridional (1962), de Fernando Henrique Cardoso, As metamorfoses do escravo (1962), de Octavio Ianni, e A integração

${ }^{1}$ Os trabalhos de Maria Sylvia de Carvalho Franco anteriores ao doutorado são dedicados, sobretudo, a questões de ordem metodológica e de socialização de estudantes na pesquisa científica, em função, talvez, de ter assumido a disciplina de "Métodos e técnicas de investigação sociológica", substituindo Florestan Fernandes, na qual dirigiu uma pesquisa sobre a clientela da Faculdade de Filosofia, cujos procedimentos e conclusões foram apresentados em um boletim da cadeira de Sociologia I, intitulado "Os alunos do interior na vida escolar e social da cidade de São Paulo: técnica e resultados de uma pesquisa de treinamento". Nesse estudo, a autora reflete sobre o pensamento científico no Brasil, afirmando que aqui faltaram as condições e os estímulos sociais para sua difusão, e aborda a formação e o treinamento de pesquisadores em ciências sociais. Segundo ela, "a única chave para realizar o tipo de civilização para o qual tendemos está na capacidade de refletir na procura de soluções para problemas inéditos" e "somente a experiência do trabalho forma o aluno para a reflexão e para a atividade criadora" (Franco, 1962). Para a autora, o aproveitamento de técnicos qualificados não é um problema diante das condições de desenvolvimento do país da década de 1950. Defende, então, que "podem as Ciências Sociais numa instituição universitária alargar seus horizontes e libertar-se das contingências da simples transmissão de conhecimentos e da produção individual” (Franco, 1962). A análise desse material, como indicam estas passagens, aponta em geral para a concordância de Franco com as orientações científicas mais gerais associadas à cadeira de Sociologia I sobre o ensino da Sociologia no Brasil. Sobre o assunto, ver Arruda (1995). 
do negro na sociedade de classes, tese de cátedra apresentada pelo próprio Florestan em 1964 e publicada no ano seguinte. Juntas, estas e outras pesquisas constroem a tese segundo a qual a escravidão constituiria uma instituição essencial que articularia a totalidade da sociedade brasileira e cujos elementos componentes permanecem em tensão na vida social mesmo no período pós-abolição. Assim, o eixo das análises extrapola a questão racial: o negro, ao ocupar um posto desprivilegiado na sociedade, resultado das desvantagens históricas definidas pela escravidão, torna-se objeto privilegiado para a compreensão das condições históricas e sociais de formação do povo, entendido como conjunto de aspirantes a novos sujeitos sociais (Bastos, 1987; Arruda, 1995; Brasil Jr., 2011).

Para Maria Sylvia de Carvalho Franco, por sua vez, embora seu trabalho seja justamente sobre uma sociedade forjada no regime escravocrata, a escravidão seria antes 338 parte de um sistema socioeconômico mais amplo, "parte em que se pode encontrar, nem mais nem menos que em outra do sistema considerado, relações sociais em cujo curso se procede à unificação dos diferentes e contraditórios elementos nele presentes" (Franco, 1997, p.13,). A ênfase analítica da pesquisa recai, igualmente, sobre as formas sociais assumidas pela grande propriedade fundiária no Brasil, especialmente no seu caráter quase autárquico, e na existência, no interior dos latifúndios, de áreas ociosas do ponto de vista da produção agrícola economicamente rentável direcionada para a exportação (1997, p.14). Essa estrutura socioeconômica desenvolvida desde a Colônia teria originado a formação de um grupo social específico entre senhores e escravos, estes últimos os responsáveis diretos pela produção agrário-exportadora.

Assim, sem minimizar a importância que a escravidão assume na formação da população "livre", a ênfase analítica na questão fundiária, na mesma medida em que aproxima 
a pesquisa de Maria Sylvia de Carvalho Franco do ensaio de Oliveira Vianna e da tradição bastante heterodoxa que sua perspectiva favorece (Botelho, 2007), afasta-a das pesquisas típicas dos seus colegas da chamada "escola sociológica paulista", e do seu próprio orientador, as quais tomam as relações entre senhores e escravos como eixo explicativo da formação social brasileira (Bastos, 2002). Se Franco recusa tomar a escravidão como modo de produção, porém, sua abordagem só ganha inteligibilidade a partir da sugestão da presença simultânea, no interior do latifúndio, da produção para a subsistência e para o mercado como práticas "constitutivas" uma da outra. Questão que se desdobra teoricamente em sua tese de livre-docência, O moderno e suas diferenças (1970), até a afirmação de que na sociedade brasileira, "os critérios extraeconômicos de categorização dos indivíduos em sociedade aparecem, reiteradamente, perturbados pelos critérios de diferenciação social fundados em situação econômica" (Franco, 1970, p.177). Em todo caso, em passagem da tese de doutorado, Maria Sylvia de Carvalho Franco não deixa dúvidas quanto ao interesse de ordem prática pelo mundo rural como crucial no encaminhamento do seu trabalho:

O que me levou nos rumos deste trabalho foram os complicados problemas da estrutura agrária que tão agudamente se fizeram sentir em vários momentos da história brasileira e que tão vivamente são experimentados nos dias presentes. Em especial, parecem-me importantes os estudos que tragam contribuição para o conhecimento do trabalhador rural, elucidando as condições sociais que presidiram à sua constituição como tipo humano e expondo as pressões que dificultam a sua integração na sociedade como um ser autônomo (Franco, 1964, p.46).

O grupo estudado pela autora é o dos homens livres pobres, homens a um só tempo: 
[...] destituídos da propriedade dos meios de produção, mas não da sua posse, e que não foram plenamente submetidos às pressões econômicas decorrentes dessa condição, dado que o peso da produção, significativa para o sistema como um todo, não recai sobre seus ombros (Franco, 1997, p.14).

Pela dupla expropriação a que esse grupo social estaria submetido, a autora fala de "homens a rigor dispensáveis, desvinculados dos processos essenciais à sociedade", uma vez que a "agricultura mercantil baseada na escravidão simultaneamente abria espaço para sua existência e os deixava sem razão de ser" (1997, p.14). A autora não deixa de afirmar, ainda, as dificuldades decorrentes da dinâmica social formada a partir da existência desse contingente de homens livres pobres para a constituição de uma sociedade de classes no Brasil (Franco, 1997, p.237).

Maria Sylvia de Carvalho Franco, porém, recusa 340 peremptoriamente qualquer ideia de "ambiguidade" ou "dualidade" para explicar a estrutura social produzida pelo latifúndio e a situação paradoxal dos homens livres pobres associada diretamente a ela. Na verdade, é justamente com o intuito de se contrapor a essa ideia que a autora põe em movimento sua pesquisa empírica e suas reflexões históricas e teóricas. Para ela, no Brasil, ao contrário do que teria ocorrido noutros contextos históricos, a simultaneidade das duas "modalidades de produção" - para a subsistência e para o mercado - não apenas indicava que se tratava de práticas "interdependentes", uma vez que encontrariam "sua razão de ser na atividade mercantil", mas propriamente "constitutivas" uma da outra (Franco, 1997, p.11).

A pesquisa realizada por Franco refere-se à "velha civilização do café", compreendida na região do Vale do Paraíba fluminense e paulista do século XIX. Sua circunscrição empírica à comarca de Guaratinguetá, uma "área mais pobre da região paulista", foi orientada, como afirma, 
pela intenção de capturar os "nexos de recorrência entre estabilidade e mudança social", uma vez que nela as "transformações vindas com o café se fizeram sentir de maneira mais branda, conservando-se as características anteriores" (1997, p.17). O objeto original da pesquisa de doutoramento, porém, não seria Guaratinguetá, e, sim, a cidade de Roseira, também no Vale do Paraíba, conforme indica uma carta de Florestan Fernandes a Roger Bastide, datada de 21 de junho de 1957, na qual dá notícias das novidades na cátedra: "Maria Sylvia passou a interessar-se por um estudo de comunidade [sic], que toma por objeto a cidade de Roseira. Para este projeto, consegui reunir auxílio de três fontes diferentes, que darão a Maria Sylvia a possibilidade de conduzir o trabalho até o fim”. Vale observar ainda que Lucila Hermann, sob cuja direção Maria Sylvia de Carvalho Franco trabalhou ao lado de Fernando Henrique Cardoso no Instituto de Administração da USP, na década de 1950, realizou importante análise histórica intitulada Evolução $d a$ estrutura social de Guaratinguetá num periodo de trezentos anos, publicada em 1948, a que Maria Sylvia de Carvalho Franco recorre em sua argumentação. O material primário de sua pesquisa é composto basicamente por atas, correspondências e processos criminais da Câmara de Guaratinguetá do período de 1830 a 1899. Dele, mobiliza com destaque os processos-crime, e é especialmente a partir da análise dos depoimentos dados à polícia contidos nesses relatos que a autora procura recuperar as "situações vividas" (Franco, 1997, p.18) pelos homens livres e pobres - indício bastante significativo da influência de Antonio Candido, então ligado à cadeira de Sociologia II, a que a própria Maria Sylvia de Carvalho Franco faz menção recorrentemente (voltaremos a esse aspecto nas considerações finais do estudo).

Para Maria Sylvia de Carvalho Franco, os homens livres pobres ganham inteligibilidade sociológica no âmbito da dominação marcada por relações diretas, pessoais e 
violentas, que formam uma rede de contraprestações de toda sorte de serviços prestados e favores recebidos. A esse respeito, Homens livres na ordem escravocrata apresenta contribuições notáveis. Em primeiro lugar, mostra como a violência característica das relações de dominação pessoal é constitutiva, também, das relações de solidariedade social internas aos grupos considerados, como mostra de modo paradigmático a análise dos mutirões como forma cooperativa de trabalho entre os "caipiras" (Franco, 1997, p.21 e ss.).

Em segundo lugar, sua análise dá atenção especial ao sentido sociológico das componentes sociais intersubjetivas presentes nas relações de dominação política pessoalizadas. A “dominação pessoal” sustentada nas relações de contraprestação é "pessoal”, argumenta a autora, justamente porque fundada numa identificação entre aqueles que delas participam como "pessoas", categoria que cria uma aparên-

342 cia de indistinção social corroborada ainda pelo "estilo de vida" simples da região, desde o início do século XIX, quando a situação de penúria material era praticamente generalizada (1997, p.115-9). Por isso, as relações de dependência aparecem antes como uma

[...] inclinação de vontades no mesmo sentido, como harmonia, e não como imposição da vontade do mais forte sobre a do mais fraco, como luta. Em consequência, as tensões inerentes a essas relações estão profundamente ocultas, havendo escassas possibilidades de emergirem à consciência dos dominados (Franco, 1997, p.95).

O compadrio, por exemplo, é uma relação paradigmática da dominação pessoal porque permite ou mesmo exige uma quebra aparente das hierarquias sociais entre aqueles que, pelo batismo, são unidos ritualmente num "parentesco divino" (Franco, 1997, p.84-6). Essa aparência de "igualdade" 
conferida pela categoria "pessoa" aos homens livres pobres, por oposição aos escravos vistos como "propriedade" ou "coisa", é fundamental porque suas relações com os senhores não são vividas diretamente como uma relação de dominação. Não apenas entre sitiantes e fazendeiros, mas também entre estes e seus agregados ou até mesmo com outras categorias sociais virtualmente menos dependentes deles, como tropeiros e vendeiros, todas elas submetidas à mesma trama de relações de fidelidades pessoais (idem, p.65-114).

Ainda que não veja na dominação política exatamente uma contrapartida para a fragilidade dos laços socioeconômicos que ligam os senhores rurais ao vasto contingente de homens livres pobres, a pesquisadora também considera a política uma área privilegiada para observar as relações de "dependência" dos grandes proprietários em relação aos seus "vizinhos menores" (1997, p.90). Mais do que isso, divisa na importância central assumida na vida política por essa relativa sujeição do senhor, traduzida numa série de obrigações de sua parte, o principal motivo que desautorizaria uma caracterização da dominação pessoal em termos de uma relação "patrimonial típica", tal como definida por Max Weber (Franco, 1997, p.91) - questão a qual voltaremos adiante com mais vagar. A autora não deixa de enfatizar ainda a desigualdade de poder envolvida nas relações de dominação pessoal, sustentando, ademais, que esse tipo de situação constituiria uma base social pouquíssimo "propícia para a orientação racional da ação" (idem, p.29).

Em suma, a pesquisa de Maria Sylvia de Carvalho Franco mostra como a "dominação pessoal" se constituiu num princípio mais geral de coordenação das relações sociais, testado em diferentes níveis complementares. Ela está presente no modo como os homens livres pobres se relacionam entre si (discutido no capítulo 1 do livro) e no modo como eles se relacionam com a sociedade inclusiva, mostrando como a dominação pessoal constitui técnica de dominação política 
nas associações com os fazendeiros (capítulo 2). Dominação pessoal que se desdobra no Estado, pois é incorporada de modo constitutivo às instituições fundidas entre público e privado (capítulo 3), e nos nexos entre a estrutura interna das fazendas cafeeiras e o exterior, atravessados pelos circuitos do capital produtivo, comercial e financeiro, cujo movimento, ao mesmo tempo, franqueou-lhes a prosperidade e levou-as à falência (capítulo 4). Desse roteiro, depreende-se seu intuito, exitoso em seus termos, a meu ver, em demonstrar a "unidade contraditória" que, "determinada na gênese do sistema colonial, sustentou, com suas ambiguidades e tensões, a maior parte da história brasileira" (Franco, 1997, p.11). Como recordaria ainda em outra oportunidade, o exame do cotidiano dos homens livres pobres "permitiu elucidar que a brutalidade não se restringiu à imediatez da escravidão: sua própria figura resultou da inclemência inerente ao capitalismo, regenerador dessa 344 instituição e base da crueza espraiada por toda a organização socioeconômica" (Franco, 1997, p.17). Ao dirigir o foco para o homem livre, portanto, visava esquivar-se das "interpretações tendenciosas, tal como atribuir a violência às mazelas do 'atraso' brasileiro, ao 'sistema escravista', absolvendo o capitalismo então considerado etapa necessária ao 'progresso' histórico" (idem, p.18).

\section{0 moderno e suas diferenças: tradição e modernidade}

"Unidade contraditória", portanto, constitui, talvez, a categoria mais próxima de uma síntese analítica da interpretação substantiva de Maria Sylvia de Carvalho Franco sobre a formação da sociedade brasileira, afinal é disso que trata Homens livres na ordem escravocrata. Não cabendo aqui fazer uma história do conceito, limito-me a chamar a atenção para o fundamental: é essa caracterização sociológica atinente à historicidade própria da formação da sociedade que permite, em primeiro lugar, explicitar o contexto inte- 
lectual mais amplo do período e o debate interno à própria cadeira de Sociologia I da USP, em que a tese/livro tomava parte e marcava uma posição própria da autora. É ela ainda que, em segundo lugar, permite a Maria Sylvia de Carvalho Franco fazer a crítica teórica mais detalhada e consistente das visões disjuntivas entre tradição e modernidade, correntes, a seu ver, nas teorias da modernização em sua época. Essa crítica, ponto de chegada da análise realizada em Homens livres na ordem escravocrata ganha o primeiro plano da narrativa e status de tema próprio na tese de livre-docência, O moderno e suas diferenças (1970), bem como em outros textos, a exemplo do artigo "Sobre o conceito de tradição”, publicado pelo Centro de Estudos Rurais e Urbanos (CERU/USP), em 1972, instituição criada por Maria Isaura Pereira de Queiroz, da cadeira de Sociologia II, em 1964.

Mobilizando materiais presentes na tese de livre-docência, Maria Sylvia de Carvalho Franco discute, nesse artigo, aspectos cruciais da sociologia política de Max Weber, como a distinção entre os conceitos de "dominação" e "poder". Seu objetivo é justamente sugerir como a "sociologia do desenvolvimento" estaria empregando as noções de "tradicional" e "moderno" e outras correlatas como oposições disjuntivas a partir de uma interpretação equivocada da teoria weberiana, filtrada via sociologia funcionalista norte-americana, em cujas "teorias da dualidade", ademais, a autora vê semelhanças com a "teoria do desenvolvimento desigual, de raízes marxistas" (Franco, 1972, p.25). Na tentativa de marcar, portanto, a "distância que separa o trabalho de Weber daqueles que ainda hoje invocam a sua herança", a autora sugere que de "imprecisões teóricas" e "falta de rigor" resultaria a ideia de "obstáculos à mudança", de "resistência de traços supostamente tradicionais, que estaria retardando a transformação para uma sociedade moderna", quando, na verdade, argumenta, "esses elementos permanecem, são produzidos e reproduzidos no interior de um sistema social" (Franco, 1972, pp.33 e 40). 
O mesmo tipo de preocupação teórica, associada à discussão de outras questões afins, já formava as linhas principais de sua tese de livre-docência, não por acaso, como se pode perceber, intitulada $O$ moderno e suas diferenças. Entre os temas nela abordados, destacam-se o par "comunidade" e "sociedade" na sociologia alemã (especialmente em Weber e Tönnies), sua reelaboração e a de outros "conceitos clássicos" no Brasil; bem como a tese da "mudança social" como uma passagem necessária da "sociedade tradicional" à "moderna" e, sobretudo, a "impropriedade" teórica dessa distinção e do conjunto de proposições feitas em torno dela para o "caso brasileiro". O sentido desse empenho parece claro: formular uma crítica à incorporação das premissas básicas da "sociologia do desenvolvimento", uma vez que, a seu ver, esta aplicava teorias "como se fossem verdades que pudessem ser desligadas do contexto de conhecimento em que ori346 ginalmente se inscreviam” (Franco, 1970, p.X).

A preocupação com a historicidade da vida social implica, seletivamente, uma releitura de Max Weber e do modo de construção dos conceitos típico-ideais na sociologia. Para Maria Sylvia de Carvalho Franco, a construção de tipos-ideais estaria relacionada à ordem dos fenômenos empíricos e históricos observáveis, buscando reter o "essencial" para a compreensão do sentido e também para a explicação causal. Conceitos como o de "estamento", por exemplo, ao qual voltaremos adiante, seriam construções típico-ideais nas quais a matéria histórica informaria a própria construção do conceito, segundo uma seleção do "essencial”. Para a autora:

Afinal, a proposição dos tipos ideais como técnicas de conhecimento adequado à cultura respeita a historicidade de suas formações sociais particulares, captando-as como totalidades constituídas pela atividade organizadora do espírito - mas, por isto mesmo, abriga uma teoria da história que 
silencia sobre os nexos necessários que as encadeiam ao longo de uma linha de desenvolvimento (Franco, 1970, pp.50-1).

Porque os tipos-ideais devem apreender o feixe de significações que dão sentido ao processo social, Franco aponta para o caráter de "totalidade" que eles encerram. Nesse sentido, eles não poderiam ser entendidos como "modelos", já que os elementos que os compõem não são independentes entre si, mas relacionados a uma articulação historicamente determinada, que lhes confere todo seu caráter significativo. A interpretação dos tipos-ideais no funcionalismo norte-americano de Talcott Parsons, tendo vista sua visão linear mais ampla do processo histórico, como se as sociedades modernas devessem convergir para um único padrão societário, incorreria neste erro crucial: tomando os tipos numa série linear desconectada dos processos históricos, eles pareciam poder funcionar como variáveis sistêmicas interligadas, intercambiáveis e generalizáveis, o que discrepava inteiramente, segundo a autora, da historicidade implicada na construção weberiana. Nesse mesmo erro básico incorreria a "sociologia do desenvolvimento" latino-americana ao incorporar acriticamente o funcionalismo parsoniano. Maria Sylvia de Carvalho argumenta, com base na leitura do livro de Parsons publicado em 1936, The structure of social action, que:

[...] o mérito de Weber foi ter introduzido conceitos gerais no conhecimento do social; sua falha foi não ter chegado à generalização completa. Este ponto de vista epistemológico (a generalização em si mesma como meta das Ciências Sociais), completamente alheio a Weber e expressamente rejeitado por ele, fornece as bases para desfigurar seu pensamento (Franco, 1970, p.51).

Não deve nos escapar o fato de esse empenho de Maria Sylvia de Carvalho Franco levá-la inclusive a questionar os 
"limites" da metodologia weberiana, de que, ademais, em parte ela própria se utiliza em sua pesquisa histórico-sociológica. Limites, para a autora, particularmente sensíveis quando se tratasse de apreender o processo de mudança social, como no caso da sociologia da modernização e, noutra chave, do seu próprio trabalho (Franco, 1970, p.51). Formulação que, à primeira vista, parece recolocar a crítica de Florestan Fernandes sobre os limites do tipo ideal ao tratar a questão da indução e da generalização na sociologia no livro clássico Fundamentos empíricos da explicação sociológica (de 1959). Confrontada a leitura da autora do tipo ideal, porém, a de Fernandes parece mais próxima ainda da de Parsons ${ }^{2}$.

Não se trata aqui de recuperar a longa análise de Maria Sylvia de Carvalho Franco sobre a apropriação de Weber por Parsons e deste pelo que enfeixa sob a designação de "sociologia do desenvolvimento". E embora tam348 bém não possamos comparar mais detidamente aqui os projetos, vale apontar, ainda assim, a importância do seu esforço teórico que, guardadas as proporções, têm afinidades muito significativas com o do sociólogo judeu-alemão refugiado e radicado nos Estados Unidos, Reinhard Bendix, na sociologia norte-americana. Resumidamente, a sociologia histórica forjada por Bendix, expressa em seu incontornável Construção nacional e cidadania, de 1964, procura formular alternativas consistentes: (1) à crença na universalidade dos estágios evolutivos, sugerindo a importância da compreensão de que o momentum dos eventos passados e a diversidade das estruturas sociais conduzem a diferentes caminhos de desenvolvimento, mesmo quando as mudanças de tecnologia são idênticas; (2) à opinião de que tradição e modernidade são mutuamente excluden-

\footnotetext{
${ }^{2}$ Para a aproximação entre Florestan Fernandes e Talcott Parsons, ver Brasil Jr.
} (2011). 
tes, sugerindo que a inter-relação causal entre essas dimensões é um problema de pesquisa empírica que não pode ser substituída por deduções lógicas, na medida em que os indícios contestam a hipótese de um processo de modernização uniforme; e, por fim, (3) à concepção de mudança social como intrínseca às sociedades, chamando a atenção para a combinação de mudanças intrínsecas com respostas a estímulos extrínsecos (Bendix, 1997).

Tendo isso em vista, e para dizer o mínimo, tanto Bendix como Maria Sylvia de Carvalho Franco partem da valorização da perspectiva histórica que identificam e recuperam na sociologia de Max Weber para criticar os usos a-históricos que a sociologia da modernização e a sociologia do desenvolvimento estariam fazendo dos seus conceitos. Em especial, na vertente funcionalista liderada por Talcott Parsons, o equívoco maior dessas abordagens seria, para ambos os autores, tomar "tipos ideais" como generalizações teóricas. E a valorização da perspectiva histórica tem o intuito, igualmente num e noutro autor, de permitir a crítica às perspectivas teóricas disjuntivas sobre "tradição" e "modernidade" e oferecer visões alternativas à sociologia, histórica em ambos os casos, mas "comparada", no caso de Bendix (ainda que Franco estenda a sua crítica também à sociologia do desenvolvimento de Gino Germani). Bastando lembrar, para corroborar a convergência sugerida, que esta problemática que estrutura as pesquisas da socióloga brasileira, ocupa toda a terceira parte de Construção nacional e cidadania, intitulada justamente "Reavaliação dos conceitos de tradição e modernidade" (Bendix, 1997, p.329 e ss.). Não pode ser desconsiderado ainda o fato de Franco ter dedicado grande parte da sua pesquisa e reflexão teórica à obra de Max Weber e sua recepção no Brasil - empenho presente tanto em suas teses como em seus artigos acadêmicos, como reconhece em seu Memorial acadêmico (Franco, 1988, p.11), embora ao mesmo tempo estranhe a identifi- 
cação da sua interpretação como weberiana (1988, p.19) - enquanto Bendix (1986) nos legou o fundamental Max Weber: um perfil intelectual, publicado em $1960^{3}$.

Para dar uma visão ao mesmo tempo mais objetiva e matizada das consequências dessa discussão sobre as relações entre teoria e história em Maria Sylvia de Carvalho Franco, vale voltar à sua análise da formação social brasileira e sua recusa em equacionar essa experiência em termos de patrimonialismo. Para tanto, pode-se comparar, ainda que brevemente, suas análises com a tese de doutorado de seu colega de cátedra, Fernando Henrique Cardoso, defendida em 1961, sob o título de Formação e desintegração na sociedade de castas: o negro na ordem escravocrata do Rio Grande do Sul, e publicada no ano seguinte com o título Capitalismo e escravidão no Brasil meridional: o negro na sociedade escravocrata do Rio Grande do Sul $l^{4}$. Investigando a configuração social da sociedade escravista numa região onde o trabalho escra350 vo não havia assumido a proporção que tomou nas áreas da plantation do país, Cardoso buscava conciliar, na tese, a perspectiva teórica de seu orientador Florestan Fernandes, então mais próxima ao funcionalismo, com a perspectiva marxista, cultivada no grupo de estudos d' $O$ Capital de Marx, da USP, entre meados dos anos 1950 e início dos 1960, a que esteve ligado (Lahuerta, 1999). Mas, também, cumpre lembrar, mostrava-se preocupado em discutir a forma patrimonialista de dominação política engendrada naquela experiência social, aproximando-se de modo próprio a Max Weber.

\footnotetext{
${ }^{3}$ Discutindo a recepção de Weber na tradição intelectual brasileira, Werneck Vianna identifica a interpretação de Maria Sylvia de Carvalho Franco - inscrita no que nomeia "paradigma paulista" - a uma perspectiva que confere centralidade explicativa às raízes agrárias de nossa formação social e ao patrimonialismo de base "societal" (Vianna, 1999, p.179). Para a recepção da sociologia alemã em geral no Brasil, consultar Villas Bôas (2006).

${ }^{4}$ Retomo aqui sinteticamente a longa argumentação comparativa feita por Maurício Hoelz Veiga Jr. (2010).
} 
A tese de Cardoso busca esclarecer o papel da dominação patrimonialista na formação do Rio Grande do Sul e seus desdobramentos e impasses na constituição de uma sociedade de classes no Brasil. A relação entre escravidão e dominação patrimonialista aponta, em seu trabalho, para a formação de uma sociedade estamental e de castas, pouco flexível e de reduzida plasticidade para enfrentar os dinamismos da expansão do capitalismo, enrijecida pelas formas autocráticas de poder que constituíam estruturas tradicionais distintas daquelas necessárias a uma ordem competitiva. Para Cardoso, a sociedade rio-grandense não apenas se organizou nos moldes de uma estrutura patrimonialista, como às "posições assimétricas na estrutura social correspondiam formas de comportamento reguladas por rígidas expectativas de dominação e subordinação" (Cardoso, 1977, p.84). E, como esclarece o próprio autor em longa nota explicativa, ele procurou utilizar em sua análise o conceito de patrimonialismo em sua formulação clássica weberiana (Cardoso, 1977, pp.100-1). O conceito de patrimonialismo assume, assim, teor explicativo na particularização do capitalismo mercantil-escravista no Brasil (Cardoso, 1977, pp.16-7).

Maria Sylvia de Carvalho Franco diverge da caracterização da ordem pessoalizada dada por Fernando Henrique Cardoso, pois recusa qualificar a sociedade brasileira como tipicamente patrimonial e nega que sua camada senhorial seja estamental (o que certamente possui ressonâncias quanto ao seu entendimento também da obra de Florestan Fernandes). Sempre evocando sua compreensão de Max Weber, no primeiro caso, Franco objeta, em Homens livres na ordem escravocrata, que não se poderia falar da configuração de uma relação patrimonial típica entre os homens livres, pois, nesta, "o amplo e exclusivo aproveitamento da força de trabalho do dependente, que é insubstituível, torna inelutável preservar sua disposição e capacidade de bem servir, o que gera uma sujeição para o senhor, definindo obrigações de sua parte" 
(Franco, 1997, p.91). No Brasil, prossegue a autora, somente no plano político verifica-se a conformação de uma solidariedade deste tipo, na qual os serviços do "cliente" são vitais para os grupos dominantes e se conjugam aos deveres que estes devem assumir e cumprir. Quando, pois, "estavam em jogo objetivos básicos como apoio político versus auxílio econômico, consolidava-se a interdependência" (idem, ibidem), do contrário, os compromissos revestiam-se de grande fragilidade - argumento que, aliás, se aproxima bastante do exposto por Oliveira Vianna (citado em Botelho, 2007). Como ainda fez questão de reforçar na entrevista "As ideias estão no lugar”, publicada em Cadernos de Debates, em 1976, na medida em que nenhuma tradição, apenas costumes frouxos e compromissos superficiais selaram o sistema de contraprestações da dominação pessoal, não se poderia falar adequadamente em relação patrimonial, "onde o amplo e exclusivo aproveitamento dos dominados como trabalhadores limita tradicio352 nalmente sua exploração, de modo a não comprometer sua disposição de bem servir" (Botelho, 2007, p.62). No Brasil, ao contrário, nada restringiu a arbitrariedade do mais forte: "o interesse material submetia à sua razão os laços de estima e da afeição, atando-os ou destruindo-os" (id., ibid.).

Quanto à caracterização estamental da sociedade brasileira, Maria Sylvia de Carvalho Franco postula que nem do ponto de vista teórico, nem na pesquisa empírica e histórica ela se sustentaria. Anota a autora a caracterização "suficientemente precisa" que a pesquisa histórica fizera de "estamento":

[...] referia-se a grupos em movimento para liberar-se das relações hierárquicas do feudalismo e que se autorreconheciam como internamente homogêneos, exigindo cartas de privilégios e liberdades. Constituíam grupos que traçavam novas divisões na sociedade, que reclamavam direitos por oposição a outros grupos, 
defendendo-se juridicamente. Eram formações sociais que surgiam sobre a ruína medieval, anunciando o processo de fundação da sociedade civil, afastando-se do juramento e das sanções transcendentes para aproximarem-se do contrato (Franco, 1997, p.10).

Todavia, este "rótulo" teria cumprido, para a autora, importante tarefa na sociologia brasileira, tarefa que qualifica de "ideológica", de separar o

[...] economicamente "irracional e improdutivo", o "socialmente violento e preconceituoso", o "politicamente reacionário", do moderno, do progressista, do último termo do milenarismo, ora escondido, ora confessado: o capitalismo como instância civilizadora. Sociedade escravista e estamental, desrazão essencialmente diversa da sociedade de classes, do trabalho livre e da racionalidade capitalista (Franco, 1997, pp.10-1).

A esse respeito, Maria Sylvia de Carvalho Franco observa em seu Memorial acadêmico, que, investigando os vínculos entre a estrutura interna das fazendas cafeeiras e o exterior, atravessadas pelos circuitos do capital produtivo, financeiro e comercial, em vez de uma rígida "sociedade estamental" "para não mencionar castas", acrescenta - "foi surgindo um mundo móvel e permeável, com estilos de vida fluidos, aliados a formas de dominação que sintetizaram a convivência pessoal e os ajustamentos abstratos em todos os âmbitos da vida, desde a esfera privada até os negócios públicos" (Franco, 1997, p.18).

E a principal razão para a retomada em chave teórica dessas questões na tese de livre-docência parece suscitada pela pesquisa empírica e teórica realizada seis anos antes para a tese de doutorado, e sua ideia de que, na sociedade brasileira, "os critérios extraeconômicos de categorização dos indivíduos em sociedade aparecem, reiteradamente, 
perturbados pelos critérios de diferenciação social fundados em situação econômica" (Franco, 1970, p.177). Assim, voltando a Homens livres na ordem escravocrata, com esse argumento em mente, percebemos como a ideia de "unidade contraditória", a que a autora chegou, remete a uma compreensão sociológica afinada à historicidade do processo social, e que se a pessoalização das relações sociais e das práticas de poder não produz as mesmas sociedades que se formavam nas experiências históricas europeias, elas respondiam de modos próprios a determinações mais gerais da expansão do capitalismo e da construção da sociedade moderna. O reconhecimento e a qualificação da historicidade da vida social, preocupação que costura o conjunto da obra sociológica de Maria Sylvia de Carvalho Franco, desautorizaria, em suma, a reificação das noções de tradicional e moderno que, a seu ver, seriam noções normativas, reincorporadas acriticamente nas interpretações dos países, àquela 354 altura, chamados "subdesenvolvidos". Como boa praticante de uma sociologia histórica, também Franco parece estar dizendo a todo momento que, afinal de contas, a interação entre tradição e modernidade constitui, por si só, um problema histórico de pesquisa, e, assim, não poderia ser substituído por qualquer dedução lógica ou ideológica. Como diz ironicamente em seu Memorial acadêmico:

Voltando ao modo genérico de pensar, em larga medida vigente nas Ciências Sociais, constatamos como no mais íntimo de seu corpus doutrinário se evidencia o corte mítico entre o mundo moderno, capitalista, regido pela universalidade abstrata, travejado por relações formais, transitivo em lutas sem sujeito, violento, rápido, e seu outro mundo comunitário e tradicional - imagem do passado ou figura do atraso - tecido em laços pessoais, exposto ao sentimento, adstrito à particularidade, harmonioso, inane (Franco, 1988, p.199) 


\section{Teoria e história: um equilíbrio delicado}

A relação entre teoria e história na sociologia forma a problemática que confere unidade à obra sociológica de Maria Sylvia de Carvalho Franco. Seja na sua interpretação substantiva do Brasil realizada em Homens livres na ordem escravocrata, seja em seus textos mais teóricos, a autora dedicou-se, como vimos, a realizar: (1) uma análise do processo de modernização alternativa às perspectivas concorrentes e, em verdade, hegemônicas da mudança social da sua época, reunidas pela designação mais genérica de "sociologia do desenvolvimento"; e (2) uma análise crítica dos pressupostos teóricos dessas perspectivas, especialmente do modo a-histórico como as categorias weberianas - substantivas, como a de patrimonialismo, e metodológicas, como a do tipo ideal - eram tomadas, sobretudo, via funcionalismo parsoniano, no Brasil e na América Latina.

Sugeri neste estudo como a categoria de "unidade contraditória", fundamental na economia argumentativa de Homens livres na ordem escravocrata, constitui o elemento cognitivo interno que permite, noutros textos da autora, a explicitação da recusa conceitual da dicotomia tradição vs. modernidade, e que a autora vê tratada como tipos de estruturas sociais contrapostos de modo dualista na "sociologia do desenvolvimento". Originada nas formas sociais assumidas pela grande propriedade agrária no Brasil, que concentrava duas modalidades de produzir, para a subsistência e para o mercado, essa "unidade contraditória" inscrita na gênese da sociedade brasileira, desdobra-se, do nível da economia, no da organização social, na síntese difícil das associações morais e das constelações de interesses, e desenvolve-se, no nível da organização política, na fusão das esferas pública e privada. Ou seja, o mesmo processo de desenvolvimento capitalista que criou as condições para a classe burguesa impor-se não apenas social e economicamente, mas também politicamente, ao conjunto da socie- 
dade feudal, reeditou as formas modernas de escravidão e gerou essa unidade contraditória entre relações de interesse, ligadas à competição e ao conflito num mercado concorrencial, e associações morais, fundadas em um jogo de privilégios e favores.

Justamente porque a autora recusa a ideia de "dualidade integrada" (Franco, 1997, p.11), talvez, valesse a pena comparar a noção da "unidade contraditória" à de "desenvolvimento desigual, mas combinado", tão associada à produção intelectual da cadeira de Sociologia I (Lahuerta, 1999; 2008). Essa comparação permitiria formular uma visão mais completa das relações entre história e teoria na sociologia de Maria Sylvia de Carvalho Franco, e implicaria, necessariamente, uma comparação detida entre as suas noções de "capitalismo" e "escravidão", bem como das relações históricas, empíricas e conceituais estabelecidas entre esses termos e aquelas do grupo de Florestan Fernandes. 356 Igualmente importante, nesse sentido, seria qualificar as críticas do grupo mais identificado à cadeira de Sociologia I comparando-as à sociologia histórica de Franco ${ }^{5}$.

\footnotetext{
${ }^{5}$ Nesse sentido, uma crítica importante a Maria Sylvia de Carvalho Franco é feita por Juarez Brandão Lopes sobre o texto "Organização social do trabalho no período colonial", apresentado pela autora em seminário da Unicamp, em 1980, cujo debate está publicado no livro Trabalho escravo, economia e sociedade. Lopes sugere que a ênfase dada pela autora na "funcionalidade" da escravidão ao capitalismo não lhe permitiria ver e qualificar as passagens do antigo regime para a sociedade burguesa de um ponto de vista mais sociopolítico, menos economicista. Já a crítica de Paulo Arantes ao modo como Franco articula pobreza e pessoalização aos requisitos de uma orientação capitalista da conduta parece equivocada, como observa Pedro Cazes, uma vez que com essa "ética protestante caipira", Franco não estaria "rebatendo os vínculos da dominação pessoal sobre o comportamento impessoal da prática lucrativa burguesa", como afirma Arantes (1992, p.72); mas, antes, mostrando como, até certo ponto, não há incompatibilidade entre o código pessoalizado e violento do mundo "rústico" e as práticas capitalistas de organização da produção (Cazes, 2010). $\mathrm{Na}$ entrevista que Lília Moritz Schwarcz e eu fizemos com Roberto Schwarz, por sua vez, há várias indicações importantes que permitem qualificar o debate entre a sua interpretação do favor na sociedade brasileira e a de Franco, inclusive seu ponto de vista sobre a acusação feita por Franco, na entrevista "As ideias estão no lugar", de 1976, de que ele estaria repondo o dualismo em sua interpretação de Machado de Assis (ver Schwarcz e Botelho, 2008).
} 
Como argumentei ao longo deste estudo, dadas as discrepâncias significativas das análises de Maria Sylvia de Carvalho Franco em relação aos trabalhos produzidos por Florestan Fernandes e seus demais orientandos e assistentes, bem como o sentido da sua crítica teórico-metodológica, a perspectiva analítica histórico-sociológica alternativa que Maria Sylvia de Carvalho Franco formula ganha inteligibilidade em relação à orientação intelectual da cadeira de Sociologia I, a que pertencia institucionalmente. Sua obra sociológica, antes problematiza que corrobora alguns dos pressupostos empíricos, históricos e teóricos dos trabalhos do seu orientador Florestan Fernandes e de seu grupo como um todo. Se constrangimentos institucionais, entre outros, não permitiram (até o momento) que a autora polemizasse abertamente com seu grupo de origem, a análise de sua obra indica uma visão crítica e uma proposição alternativa, sobretudo pela forte ênfase que dá ao relacionamento entre teoria e história na explicação sociológica. Maria Sylvia de Carvalho Franco não se refere de fato a Florestan Fernandes em suas críticas, prefere reservar explicitamente a Gino Germani críticas que parecem implicitamente direcionadas igualmente a seu orientador. Ou que ao menos poderiam ser assim interpretadas, dada a identificação entre as obras dos dois principais sociólogos da América Latina de sua geração, e a recepção igualmente importante neles, embora com distinções em nada desprezíveis, do funcionalismo norte-americano que cada um ao seu modo contesta e recria (Brasil Jr., 2011) - o que a autora, por sua vez, tampouco reconhece.

Mais do que a contraposição nomeada, porém, o que mais chama a atenção são os silêncios de Maria Sylvia de Carvalho Franco em relação a Florestan Fernandes e seus outros discípulos. É o caso da sua contraposição em relação à não pertinência da ideia de estamento, central em Florestan Fernandes, e de patrimonialismo, segundo a 
interpretação de Fernando Henrique Cardoso, que comparamos à sua, embora neste último caso o debate seja, discretamente, nomeado. Tampouco nos textos reflexivos sobre sua trajetória intelectual, como seu Memorial acadêmico e as muitas entrevistas que tem concedido, Franco se demora na orientação de Florestan. No Memorial acadêmico, o contraste entre o silêncio sobre Florestan Fernandes e sua avaliação da importância de Antonio Candido para a sua formação, especialmente d'Os parceiros do Rio Bonito, chega a ser algo constrangedor. Sobre Florestan, a quem dedicou, porém, Homens livres na ordem escravocrata (e, como se sabe, Maria Sylvia de Carvalho Franco aparece junto aos demais assistentes de Florestan na dedicatória de A revolução burguesa no Brasil, de 1975), ela limitou-se, salvo engano, a observar, numa entrevista publicada em 1981, que, ao lado de Antonio Candido, ele teria sido "outra influência decisiva nos rumos da minha produção intelectual”, para logo qualifi358 car: "Primeiro o mestre admirado, depois o opositor respeitado. Nossas divergências mantiveram-se na maior confiança e lealdade, padrão que hoje parece estar desaparecendo da cena universitária” (Franco, 1988, p.9).

São muitas as menções a Os parceiros do Rio Bonito, tese de doutoramento em ciências sociais apresentada em 1954 à Faculdade de Filosofia, Ciências e Letras da Universidade de São Paulo, onde, até aquele momento, Antonio Candido desempenhava, havia dezesseis anos, a função de assistente da cadeira de Sociologia II, e publicada em livro somente dez anos depois, em 1964. Em seu Memorial acadêmico, por exemplo, a autora escreve que Os parceiros foi de importância decisiva em seus esforços para coadunar reflexão e linguagem (1988, p.20), chamando-lhe a atenção para a necessidade de escapar da linguagem cifrada do jargão sociológico e de escrever de modo mais acessível (1988, p.9). E nenhum outro livro da sociologia brasileira, à exceção do seu próprio, é analisado com tanto vagar e 
cuidado no Memorial - é verdade que a análise é interrompida por um longuíssimo excurso sobre as raízes aristotélicas das modernas ciências sociais de cerca de oitenta páginas. Vale citar uma passagem decisiva a respeito do livro clássico de Antonio Candido:

À diferença das "introduções metodológicas" - muito em voga na época - que repetiam assertivas dogmáticas no jargão competente, a abertura de seu livro [de Antonio Candido] nos permite seguir, de verdade, uma atitude estudiosa, um olhar que busca alternativas teóricas, que tateia, vacila, recusa e escolhe, face aos vários caminhos oferecidos pelas ciências sociais [...] O caminho escolhido recusa a generalidade abstrata do sociólogo, declinando, no mesmo passo, o recorte descritivo dos "estudos de comunidade" [...] Procedimento crucial, onde o pensamento rompe com o abstrato (empírico ou lógico), o que permitirá ao pesquisador valer-se das representações do caipira não enquanto dobrada sobre si mesma (fechada no bairro, como na precisa análise da consciência grupal que abre o primeiro capítulo), mas como reflexão que se amplia sobre a sociedade brasileira (como os capítulos sobre as transformações) (Franco, 1988, pp.107-8).

Não tenho como comentar todas as cerca de oito páginas dedicadas por Maria Sylvia de Carvalho Franco à análise bastante fina do livro de Antonio Candido, nas quais, e por meio das quais, ela fala muito dela também, já que Os parceiros são evocados pela sua influência em sua própria trajetória intelectual reconstruída no Memorial. E o leitor terá acertado se tiver percebido a identificação, na citação feita acima, entre o plano apresentado do livro de Antonio Candido e o dela própria, Homens livres na ordem escravocrata. Mas note mais o leitor, que a valorização de Antonio Candido se dá, talvez, sobretudo em função da postura pioneira em evitar as solu- 
ções teóricas fáceis - a "generalidade abstrata do sociólogo", como diz Maria Sylvia de Carvalho Franco. Então, voltamos mais uma vez ao tema principal deste estudo.

Será mesmo possível sociologia sem generalização? A questão certamente não tem uma resposta unívoca, se é que é apropriado falar, nesse caso, até mesmo em respostas. De todo modo, do ponto de vista da análise que propomos da obra sociológica de Maria Sylvia de Carvalho Franco, o problema talvez esteja menos na generalidade do que no tipo de generalidade apontada pela autora: a generalidade "abstrata" que, ingenuamente ou não, simplifica e deforma a realidade. Assim, parece razoável, depreender que a autora não desconhece ou rechaça a relação tensa entre história e teoria nas ciências sociais, mas defende o uso da história para qualificar, ampliar ou restringir o alcance da teoria. Sejam quais tenham sido as raízes da sociologia histórica formulada por essa autora, não se pode deixar de reconhe360 cer quanto sua proposta é convergente em termos cognitivos com a reação ao funcionalismo na sociologia histórica em geral. Reação que, como já foi mostrado, firmemente enraizada em rico material histórico, acabou por revalorizar o papel dos atores humanos - individuais e coletivos - como os criadores últimos do mundo social em transformação (Stompka, 1998).

E em estudo anterior (Botelho, 2009), discutindo o potencial teórico heurístico da reconfiguração não disjuntiva da relação ação/estrutura na sociologia histórica de Maria Sylvia de Carvalho Franco, numa comparação com a obra de Maria Isaura Pereira de Queiroz, a quem aquela esteve ligada em diferentes frentes, mostrei que a autora consegue divisar tanto aspectos persistentes na organização e reprodução social, como a própria capacidade manifesta por indivíduos e grupos sociais de agirem e, desse modo, de responderem criativamente ao contexto de estruturas em que se inserem. É verdade que Maria Sylvia de Carvalho Franco procura 
demonstrar os limites da mudança institucional decorrentes da generalização da dominação pessoal como princípio de coordenação social, mas não deixa de considerar, porém, as forças sociais que compõem dinamicamente a relação Estado/sociedade e, sobretudo, os atores sociais que as sustentam - como no caso do servidor público por ela analisado. Guardando importantes afinidades com a sociologia política de Max Weber (1992), as bases sociais da dominação política são importantes na pesquisa da autora, tendo em vista não apenas o problema da "legitimidade", como também as razões de as próprias instituições ou outras formações sociais serem compreendidas como resultados das ações e do entrelaçamento de ações de homens comuns que, ao atribuírem sentidos a suas ações, não deixam de levar em conta as próprias restrições da sua situação ${ }^{6}$.

Porque as velhas dicotomias entre tradição e modernidade, continuidade e mudança, sincronia e diacronia, ação e estrutura simplesmente não desapareceram, a despeito do avanço coletivo da sociologia histórica, a tensão entre teoria e história continua a interpelar as ciências sociais (Skocpol, 1984; Reis, 1998), em especial a sociologia política (Botelho, 2011; Alonso e Botelho, 2012). E a esta tensão se deve, em grande medida, o sentido teórico heurístico da obra de Maria Sylvia de Carvalho Franco. Seu interesse está para além da conformação particular de diretrizes teóricas gerais que encerra, das inevitáveis adaptações mais ou menos criativas a que contextos cognitivos tradicionalmente consumidores da teoria sociológica parecem destinados sempre que confrontados a uma realidade empírica distinta dos "centros" da sociologia mundial. Mas na medida mesmo em que, como no caso de Homens livres na ordem escravocra$t a$, a pesquisa empírica historicamente orientada provoca

${ }^{6}$ Sobre a sociologia política de Weber, consultar o livro clássico de Bendix (1986). Sobre a sociologia política de Maria Isaura Pereira de Queiroz, ver Botelho (2007; 2009) e Botelho e Carvalho (2011). 
questionamentos consequentes à própria teoria social, e às possibilidades de combinação entre componentes empíricos, históricos e analíticos em geral, cumpre reconhecer sua capacidade de interpelação à compreensão daquilo que, para recorrer a uma definição sintética do objeto da sociologia dada por Marcel Mauss (2003, p.187), simplesmente, constitui a "vida propriamente social das sociedades".

Esse reconhecimento não deve nos levar, porém, a ignorar duas questões relacionadas, uma de ordem geral sobre a obra sociológica de Maria Sylvia de Carvalho Franco perante a sociologia brasileira, outra relativamente aos desenvolvimentos, por assim dizer, internos de sua obra, com as quais queremos concluir o presente estudo, mas que não podemos senão indicar para futuras investigações. Comecemos pela última questão.

As assertivas de Maria Sylvia de Carvalho Franco em estudos posteriores sobre a perenidade do seu diagnósti362 co sobre a sociedade brasileira em conjunturas históricas tão diferentes daquela do seu estudo empírico original restringem, talvez, a validade da sua visão de história e teoria aqui discutida justamente em seus trabalhos das décadas de 1960-70. Penso em alguns dos seus estudos acadêmicos posteriores, como aquele sobre as tensões imprimidas pela sociedade brasileira à industrialização que nela se processava, em torno na década de 1950, em artigo publicado na Revue Tunisienne de Sciences Sociales (Franco, 1974), ou mesmo nos muitos artigos de conjuntura política sobre o Brasil contemporâneo, que vem publicando na grande imprensa, no quais, no limite, a realidade social parece deixar de ser um processo dinâmico e se torna um estado constante.

No entanto, do mesmo modo, o alcance próprio da crítica de Maria Sylvia de Carvalho Franco poderá ser mais bem qualificado levando em conta que, como começa a ser demonstrado sistematicamente (Brasil Jr., 2011), a recepção da "sociologia da modernização" norte-americana não foi 
simplesmente passiva nas obras de Florestan Fernandes e seu grupo ou de Gino Germani, dois dos principais vezos da renovação da sociologia na América Latina. Ao contrário, implicou traduções intelectuais ativas nas quais, inclusive, alguns dos pressupostos básicos do funcionalismo, como a concepção de que as sociedades modernas convergiriam para um único padrão societário, foram tensionados pela força que a história assumiu, ainda que progressivamente, nas suas explicações. Ao que tudo indica, porém, não estamos exatamente diante de uma questão de gradiente, de mais ou menos história na explicação, mas de sentidos qualitativos distintos, assumidos pela história na economia interna dos argumentos e, assim, na sociologia produzida por esses diferentes autores. E, assim, voltamos ao tema principal deste estudo.

\section{André Botelho}

é professor do Departamento de Sociologia e do Programa de Pós-Graduação em Sociologia e Antropologia da Universidade Federal do Rio de Janeiro (PPGSA-UFRJ) e pesquisador do CNPq e da Faperj.

\section{Referências bibliográficas}

ALONSO, A.; BOTELHO, A. 2012. "Repertórios de ação coletiva e confrontos políticos: entrevista com Sidney Tarrow". Sociologia E Antropologia, v.2, pp.11-20.

ARANTES, P. 1992. Sentimento da dialética na experiência intelectual brasileira: dialética e dualidade segundo Antonio Candido e Roberto Schwarz. Rio de Janeiro: Paz e Terra.

ARRUDA, M. A. N. 1995. "A sociologia no Brasil: Florestan Fernandes e a 'Escola Paulista'”. In: MICELI, S. (org.). História das Ciências Sociais no Brasil. São Paulo: Sumaré/Fapesp. v. II.

BASTOS, E. R. 1987. "A questão racial e a revolução burguesa”. In:

D’INCAO, M. A. (org.). O saber militante. Ensaios sobre Florestan Fernandes. Rio de Janeiro/São Paulo: Paz e Terra/Unesp.

2002. "Pensamento social da escola sociológica paulista". In: MICELI, S. (org.). O que ler na ciência social brasileira: 1970-2002. São Paulo/Brasília: Anpocs/Sumaré/Capes, pp.183-230. v.IV. 
BENDIX, R. 1986 [1960]. Max Weber, um perfil intelectual. Brasília: UnB. 1997. Construção nacional e cidadania. São Paulo: Edusp.

BOTELHO, A. 2007. "Sequências de uma sociologia política brasileira".

Dados, v. 50, pp.48-82. . 2009. "Dominação pessoal e ação na sociologia política

brasileira”. In: FERRETI, S. F.; RAMALHO, J. R. (orgs.). Amazônia: desenvolvimento, meio ambiente e diversidade sociocultural. São Luís: EdUfma. 2011. "Political sociology". In: Sociopedia. ISA. London: Sage. .; CARVALHO, L. C. 2011. "A sociedade em movimento: dimensões da mudança na sociologia de Maria Isaura Pereira de Queiroz”. Sociedade e Estado, Brasília: UnB, v.26, pp.209-38.

BRASIL Jr., A. 2011. Passagens para a teoria sociológica: Florestan Fernandes e Gino Germani. Tese de doutorado em Sociologia. Rio de Janeiro. Programa de Pós-graduação em Sociologia e Antropologia da Universidade Federal do Rio de Janeiro.

CARDOSO, F. H. 1977 [1962]. Capitalismo e escravidão no Brasil meridional: o negro na sociedade escravocrata do Rio Grande do Sul. Rio de Janeiro: Paz e Terra.

CAZES, P. 2010. Relatório de pesquisa Faperj. Rio de Janeiro: Departamento de Sociologia/IFCS/UFRJ. (Mimeo).

FERNANDES, F. 1957. Carta a Roger Bastide. São Paulo, 21 de junho de 1957. Disponível no Fundo Florestan Fernandes da Biblioteca Comunitária da Universidade Federal de São Carlos, São Paulo. s.d. Anotações de Florestan Fernandes feitas na defesa de tese de doutorado de Maria Sylvia de Carvalho Franco. Disponível no Fundo Florestan Fernandes da Biblioteca Comunitária da Universidade Federal de São Carlos, São Paulo.

FRANCO, M. S. de. 1962. "Os alunos do interior na vida escolar e social da cidade de São Paulo: Técnica e resultados de uma pesquisa de treinamento". Boletim 259 da Cadeira de Sociologia I da FFCL-USP, São Paulo. . 1963. "O estudo sociológico de comunidades". Revista de Antropologia, v.11, n.1 e 2. . 1964. Homens livres na velha civilização do café. São Paulo. Tese de doutorado. Departamento de Ciências Sociais/Faculdade de Filosofia, Letras e Ciências Humanas da Universidade de São Paulo. . 1970. O moderno e suas diferenças. São Paulo. Tese de livre-docência. Departamento de Ciências Sociais/Faculdade de Filosofia, Letras e Ciências Humanas da Universidade de São Paulo. . 1972. "Sobre o conceito de tradição". Cadernos CERU/USP, n.5. 
1974. "Tradition et industrialisation au Brésil". Revue Tunisienne de Sciences Sociales, n.36, 37, 38, 39.

1988. Memorial acadêmico de Maria Sylvia de Carvalho Franco. São

Paulo. Tese de livre-docência. Faculdade de Filosofia, Letras e Ciências

Humanas da Universidade de São Paulo. (Mimeo). . 1976. “As ideias estão no lugar”. Cadernos de Debates, n.1. São Paulo:

Brasiliense. 1997. Homens livres na ordem escravocrata. São Paulo: Unesp. . 1984. "Organização social do trabalho no período colonial”. In: PINHEIRO, P. S. (org.). Trabalho escravo, economia e sociedade. Rio de Janeiro: Paz e Terra.

HOELZ VEIGA Jr, M. 2010. Homens livres, mundo privado. Violência e pessoalização numa sequencia sociológica. Rio de Janeiro. Dissertação de mestrado em Sociologia. Programa de Pós-graduação em Sociologia e Antropologia da Universidade Federal do Rio de Janeiro.

JACKSON, L. C. 2002. A tradição esquecida. Os parceiros do Rio Bonito e a sociologia de Antonio Candido. Belo Horizonte/São Paulo: UFMG/Fapesp.

LAHUERTA, M. 1999. Intelectuais em transição: entre a política e a profissão. São Paulo. Tese de doutorado. Departamento de Ciência Política da Faculdade de Filosofia, Letras e Ciências Humanas da Universidade de São Paulo. . 2008. "Marxismo e vida acadêmica: os pressupostos intelectuais da crítica uspiana ao nacional-desenvolvimentismo”. In: BOTELHO, A. et al. O moderno em questão: a década de 1950 no Brasil. Rio de Janeiro: Topbooks.

LAMOUNIER, B. 1982. "A ciência política no Brasil: roteiro para um balanço crítico”. In: A ciência política nos anos 80 . Brasília: UnB.

MALAGUTI, P. C. 2010. Relatório técnico-científico. PIBIC/CNPq/ Universidade Federal do Rio de Janeiro. (Mimeo).

MAUSS, M. 2003. Sociologia e antropologia. São Paulo: Cosac Naify.

PULICI, C. 2008. Entre sociólogos: versões conflitivas da "condição de sociólogo" na USP dos anos 1950-1960. São Paulo: Edusp/Fapesp.

REIS, E. P. 1998. "Generalização e singularidades nas ciências humanas". In: Processos e escolhas: estudos de sociologia política. Rio de Janeiro: Contra Capa.

SALLUM Jr., B. 2002. "Notas sobre a gênese da sociologia política em São Paulo”. Política e Sociedade, Florianópolis, v.1, n.1.

SCHWARCZ, L.; BOTELHO, A. 2008. "Ao vencedor as batatas 30 anos: crítica da cultura e processo social: entrevista com Roberto Schwarz". Revista Brasileira de Ciências Sociais, v.23, n.67, pp.147-60. 
SKOCPOL, T. 1984. Vision and method in historical sociology. Cambridge: Cambridge University Press.

SPIRANDELLI, C. C. 2009. Trajetórias intelectuais: professoras do curso de ciências sociais da FFCL-USP (1934-1969). São Paulo. Tese de doutorado em Sociologia. Programa de Pós-graduação em Sociologia da Universidade de São Paulo.

SZTOMPKA, P. 1998. A sociologia da mudança social. Rio de Janeiro: Civilização Brasileira.

VIANNA, L. W. (1999). "Weber e a interpretação do Brasil". In: SOUZA, J. (org.). O malandro e o protestante. A tese weberiana e a singularidade cultural brasileira. Brasília: UnB.

VILLAS BÔAS, G. 2006. A recepção da sociologia alemã no Brasil. Rio de Janeiro: Topbooks.

WEBER, M. 1992. Economía y sociedad. México, DF: Fondo de Cultura Económica. 


\section{TEORIA E HISTÓRIA NA SOCIOLOGIA BRASILEIRA: A CRÍTICA DE MARIA SYLVIA DE CARVALHO FRANCO}

\section{ANDRÉ BOTELHO}

Resumo: Inserido em pesquisa mais ampla sobre as sequências da sociologia política no Brasil, o trabalho destaca a obra sociológica de Maria Sylvia de Carvalho Franco. Assimilada à produção da cadeira de Sociologia I da USP, pelo seu pertencimento institucional, a obra desta autora, porém, antes problematiza que corrobora alguns dos pressupostos da teoria do desenvolvimento associados aos trabalhos de Florestan Fernandes e seu grupo. A análise de suas teses de doutorado (1964) e de livre-docência (1970), entre outros textos, indica uma visão crítica, e uma proposição alternativa, sobre a contraposição entre "tradição" e "modernidade" na análise da sociedade brasileira em virtude da gênese essencialmente moderna dessa experiência social.

Palavras-chave: Sociologia Brasileira; Teoria Social Comparada; Teoria e História; Tradição e Modernidade.

\section{THEORY AND HISTORY IN BRAZILIAN SOCIOLOGY: THE CRITIQUE OF MARIA SYLVIA DE CARVALHO FRANCO}

Abstract: As part of a broader research about the sequences of political sociology in Brazil, the article stress the sociological work of Maria Sylvia de Carvalho Franco. Although subsumed under the production of the chair of Sociology I of the University of São Paulo because of its institutional belonging, Franco's work questions rather than confirms some of the presuppositions of development theory linked to the works of Florestan Fernandes and his research group. The analysis of her doctoral (1964) and associate professorship (1970) theses, among other texts, shows a critical view, and an alternative proposition about the contrast between tradition and modernity in the investigation of Brazilian society as a result of the essentially modern origin of this social experience. 
Keywords: Brazilian Sociology; Comparative Social Theory; Theory and History; Tradition and Modernity.

Recebido: 07/03/2013 Aprovado: 10/06/2013 